\title{
Adherence to home ventilation therapy in patients with Obstructive Sleep Apnea Syndrome: prevalence, determinants and costs of non-compliance. A cross-sectional study
}

\author{
MARIANA MARTINS ${ }^{1, A-F}$, RAFAELA PASSOS ${ }^{2, A-F}$, JOANA PEIXOTO ORCID ID: 0000-0002-7807-876X $^{3,-F}$, CHRISTELLE COSTA ${ }^{4, ~ A-F}$, \\ LUÍS MENDES ${ }^{5, A-F}$, PAULO SANTOS ${ }^{6,7,4-F}$, RUI NÊVEDA ${ }^{8, ~ A-F}$
}

${ }^{1}$ USF Uarcos, Alto Minho Local Health Unit, Viana do Castelo, Portugal

2 USF Gil Eanes, Alto Minho Local Health Unit, Viana do Castelo, Portugal

${ }^{3}$ USF Mais Saúde, Alto Minho Local Health Unit, Viana do Castelo, Portugal

${ }^{4}$ USF Arquis Nova, Alto Minho Local Health Unit, Viana do Castelo, Portugal

${ }^{5}$ USF Baião, ACES Tâmega I, Baião, Portugal

${ }^{6}$ Faculty of Medicine, University of Porto, Portugal

${ }^{7}$ CINTESIS - Center for Health Technology and Services Research, University of Porto, Portugal

${ }^{8}$ Pulmonology department, Alto Minho Local Health Unit, Viana do Castelo, Portugal

A - Study Design, B - Data Collection, C - Statistical Analysis, D - Data Interpretation, E - Manuscript Preparation, F - Literature Search, G - Funds Collection

Summary Background. Obstructive sleep apnea (OSA) is a common chronic disease with high impact both as an independent cardiovascular risk factor and in quality of life. Home positive pressure ventilation is the main available therapeutic intervention, depending on its utilization by patients.

Objectives. Our aim was to determine the adherence to home ventilation therapy, prospecting for the determinants of compliance. Secondarily, we evaluated the direct costs of non-adherence.

Material and methods. We conducted a cross-sectional study based on retrospective analysis of a sample of 1,183 OSA patients followed in a pulmonology department during 2018. Patients with less than 180 days of utilization were excluded. The adherence to ventilation therapy was defined by utilization of more than 4 hours a day, at least $70 \%$ of the days. Costs were calculated using Portuguese official prices for reimbursement.

Results. A total of 744 patients were included for analysis. The adherents were $63.4 \%$ (95\% Cl: 60.5-67.4\%). Ageing $(p=0.014)$, severity of disease at diagnosis $(p=0.044)$, room sharing $(p=0.002)$, working in the primary economic sector $(p=0.014)$ and using $\operatorname{BiPAP}(p=$ $0.046)$ were associated with higher adherence. The total costs of non-adherence were estimated at $112,373.68 €$.

Conclusions. The adherence of patients to treatments is a relevant topic of discussion. Our results are concordant with literature, reinforcing the importance of holding the patient accountable to improve compliance with treatment. Adherence is lower than necessary to achieve the maximization of the therapeutic benefits, leading to a higher burden of disease, higher costs and significant waste. Key words: obstructive sleep apnea, noninvasive ventilation, continuous positive airway pressure, treatment adherence and compliance, health care costs.

Martins M, Passos R, Peixoto J, Costa C, Mendes L, Santos P, Nêveda R. Adherence to home ventilation therapy in patients with Obstructive Sleep Apnea Syndrome: prevalence, determinants and costs of non-compliance. A cross-sectional study. Fam Med Prim Care Rev 2021; 23(2): 185-189, doi: https://doi.org/10.5114/fmpcr.2021.105921.

\section{Background}

Obstructive sleep apnea (OSA) is a highly prevalent chronic disease [1]. It is characterized by recurrent episodes of total (apnea) or partial (hypopnea) cessation of oronasal airflow, caused by a collapse of the upper airway during sleep [2]. Its severity is labeled by the number of registered events during a polysomnography or cardiorespiratory study - Apnea/ /Hypopnea Index (AHI). An AHI between 5 and 14 is classified as mild, between 15 and 29 as moderate and values over 30 as severe [3]. This disease predominantly affects males, and obesity is a major determinant directly related to its prevalence [1]. In general, it occurs in between $9 \%$ and $38 \%$ of the population, even though moderate and severe OSA reaches considerable values of $6 \%$ to $17 \%$. The prevalence increases with age, affecting almost half of the elderly population [1]. In Portugal, a cross-sectional study performed using the Portuguese General Practitioner Sentinel Network (Rede Médicos Sentinela) found a prevalence of OSA in the population 25 years of age or more of $0.89 \%$, and it was higher in those between 65 and 74 years of age $(2.35 \%)$ [4]. OSA is a risk factor for arterial hypertension and cardiovascular disease and has a significant impact on quality of life. It might also cause neuropsychological changes, leading to the occurrence of both occupational and road accidents [5-7].

In addition to lifestyle modifications, home positive pressure ventilation is the gold standard therapeutic intervention, either continuous (CPAP) or variable (auto-CPAP or APAP) [8]. $\mathrm{Bi}-$ level ventilation (BiPAP) may be useful in treating some forms of restrictive lung disease or hypoventilation syndromes associated with hypercapnia [9]. This is a proven cost-effective 
treatment when both indirect and direct costs are considered [10-13]. With ventilation therapy, respiratory events and micro-awakenings disappear, sleep fragmentation is corrected, oxygen saturation normalizes and blood pressure fluctuations decrease, leading to improved sleep quality, reduced daytime sleepiness and enhanced quality of life [14].

In Portugal, every patient suspected of OSA is referred to a sleep study unit, generally at the hospital pulmonology department, to confirm the diagnosis and to determine the course of treatment. The first prescription of non-invasive ventilation therapy, if needed, is performed, and patients will initially be followed up by this department. After the adaptation period and at least three hospital appointments, the monitoring of patients is carried out annually at the primary care level if they are clinically stable and present a confirmed adherence to treatment $[15,16]$. Primary care assumes the main responsibility in the efficient management of ventilation therapy over time. However, contrary to the hospital, primary care doctors do not have direct access to the ventilation therapy report. The patients' collaboration is required to get the report from the respiratory care supplier and to bring it to the appointment. Although this is the case most of the time, this is a real conditioner regarding the follow-up of these patients and the management of adherence.

The problem of non-adherence to treatment by OSA patients is complex and multifactorial. The main causes of non-compliance are the patient's literacy, lack of family support, especially the partner, psychological factors (such as personality profile or existence of psychopathology, such as claustrophobia), other associated sleep disorders, factors related to treatment (iatrogenic) and home support [15].

\section{Objectives}

Our aim was to establish the prevalence of adherence to home ventilation therapy in patients with OSA, prospecting for determinants of compliance. Secondarily, we intended to estimate the direct costs associated with compliance during the study period.

\section{Material and methods}

This is an analytical retrospective observational study. We included patients 18 years of age or over with a diagnosis of $\mathrm{Ob}$ structive Sleep Apnea Syndrome (ICD-10 G47.33) and prescription of ventilation therapy, evaluated in the pulmonology department of Alto Minho Local Health Unit (ULSAM) between January $1^{\text {st }}$ and December $31^{\text {st }}, 2018$. Patients with a report less than 180 days on the use of home ventilation therapy were excluded.

ULSAM is a health institution with integrated management of primary and secondary care in the district of Viana do Castelo, Alto Minho, a region in the North of Portugal. According to the national official data (www.ine.pt), there are 244,836 inhabitants in a territorial area of 2,213 $\mathrm{km}^{2}$. From electronic clinical files, we collected sociodemographic data (gender and age), economic status, educational level, professional situation, job, room sharing, classification of the initial severity of OSA, body mass index (BMI), smoking habits, distance from home to healthcare facilities and adaptation difficulties to the ventilatory device. The type of device (CPAP, APAP or BiPAP), time under evaluation, the proportion of global daily use and the percentage of utilization less than four hours per day were obtained from the reports.

The adherence to ventilatory therapy was defined by the utilization of the device for more than 4 hours a day, at least $70 \%$ of days under prescription $[15,16]$.

The costs associated with non-adherence to therapy took into consideration the official unitary cost of the services contracted with the Portuguese Ministry of Health, which include outpatient service provision and supply of equipment [17].
Non-adherence days were retrieved from device reports and multiplied by the ventilation therapy's daily costs to obtain the estimate of annual costs related to non-compliance.

The study was approved by the Ethics Committee of ULSAM. Data was retrieved from the electronic clinical file, maintaining the anonymity of patients and respecting the principles of the Helsinki Declaration and Oviedo Convention on research in human beings.

Data analysis was performed using SPSS software, version 25.

The population was characterized using descriptive measures of trend and dispersion appropriate to the observed distribution of variables for population characterization. Confidence intervals were calculated by the modified Wald method. The Kolgomorov-Smirnov test was used to determine the normality of the distribution in continuous variables. Inferential analysis used logistic regression in a multivariate model that included variables with statistical significance in univariate analysis. An alpha error of 0.05 was considered.

\section{Results}

\section{Baseline characteristics}

A total of 1,183 patients with OSA on ventilation therapy were evaluated in the pulmonology department between January and December 2018; of these, 744 met the inclusion criteria. The mean time under evaluation was 268 ( \pm 132$)$ days. The median age was 64 years of age (interquartile range (IQR) $=18$ ), and most patients were males (70.6\%). In the socioeconomic characterization, many of the patients studied 9 years or less, almost half (44.1\%) had economic insufficiency, $44.4 \%$ were retired, and those employed were distributed mainly in the secondary and tertiary sectors. Most of patients were obese (62.5\%), shared a room with their partner (86.3\%) and lived 27 $\mathrm{Km}(\mathrm{IQR}=37)$ away from healthcare facilities. Adaptation difficulties were recorded in $46.1 \%$ of patients, $76.3 \%$ of which corresponded to leaks in the device. The patients' general characteristics are shown in Table 1.

\begin{tabular}{|c|c|}
\hline Characteristics & \\
\hline $\begin{array}{l}\text { Gender }[n(\%)](n=744) \\
\text { male } \\
\text { female }\end{array}$ & $\begin{array}{l}525(70.6 \%) \\
219(29.4 \%)\end{array}$ \\
\hline Age (median, IQR) $(n=744)$ & $64(18)$ \\
\hline $\begin{array}{l}\text { Time (years) since diagnosis (median, IQR) } \\
(n=744)\end{array}$ & $3.1(4.1)$ \\
\hline $\begin{array}{l}\text { Severity }[n(\%)](n=744) \\
\quad \text { mild } \\
\text { moderate } \\
\text { severe }\end{array}$ & $\begin{array}{l}92(12.4 \%) \\
204(27.4 \%) \\
423(56.6 \%) \\
\end{array}$ \\
\hline $\begin{array}{l}\text { Therapy }[n(\%)](n=744) \\
\text { APAP } \\
\text { BIPAP } \\
\text { BIPAP-ST } \\
\text { CPAP }\end{array}$ & $\begin{array}{l}650(87.3 \%) \\
28(3.8 \%) \\
35(4.7 \%) \\
31(4.2 \%)\end{array}$ \\
\hline $\begin{array}{l}\text { Education }[n(\%)](n=132) \\
9 \text { years or less } \\
10-12 \text { years } \\
\text { higher }\end{array}$ & $\begin{array}{l}104(78.8 \%) \\
12(9.1 \%) \\
16(12.1 \%) \\
\end{array}$ \\
\hline $\begin{array}{l}\text { Socioeconomic status }[n(\%)](n=744) \\
\text { low } \\
\text { middle and high }\end{array}$ & $\begin{array}{l}328(44.1 \%) \\
416(55.9 \%) \\
\end{array}$ \\
\hline $\begin{array}{l}\text { Workforce situation }[n(\%)](n=716) \\
\text { active } \\
\text { inactive } \\
\text { unemployed } \\
\text { retired }\end{array}$ & $\begin{array}{l}292(40.8 \%) \\
106(13.1 \%) \\
12(1.7 \%) \\
318(44.4 \%)\end{array}$ \\
\hline
\end{tabular}




\begin{tabular}{|c|c|}
\hline Characteristics & \\
\hline $\begin{array}{l}\text { Economic sector }[n(\%)](n=528) \\
\text { primary } \\
\text { secondary } \\
\text { tertiary } \\
\end{array}$ & $\begin{array}{l}136(25.8 \%) \\
196(37.1 \%) \\
196(37.7 \%)\end{array}$ \\
\hline $\begin{array}{l}\text { Smoking habits }[n(\%)](n=733) \\
\text { never smoked } \\
\text { former smoker } \\
\text { current smoker } \\
\end{array}$ & $\begin{array}{l}447(61.0 \%) \\
226(30.4 \%) \\
60(8.2 \%) \\
\end{array}$ \\
\hline \begin{tabular}{|l} 
Obesity [n $(\%)](n=736)$ \\
normal \\
overweight \\
obesity class I \\
obesity class II \\
obesity class III \\
\end{tabular} & $\begin{array}{l}50(6.8 \%) \\
226(30.4 \%) \\
245(33.3 \%) \\
133(18.1 \%) \\
82(11.1 \%) \\
\end{array}$ \\
\hline $\begin{array}{l}\text { Distance from home to healthcare facilities (me- } \\
\text { dian, IQR) }(n=744)\end{array}$ & $27(37)$ \\
\hline Sharing room $[n(\%)]$ & $587(86.3 \%)$ \\
\hline Difficulty to adapt to the device $[n(\%)]$ & $343(46.1)$ \\
\hline
\end{tabular}

IQR - interquartile range, SD - standard deviation.

Overall, the mean initial AHI was $38.5 \pm 23.5$. Most of the patients had severe OSA at diagnosis (56.6\%), $27.4 \%$ were moderate, and only $12.4 \%$ presented mild OSA. The median time from diagnosis was $3.1 \pm 4.1$ years.

Regarding the therapy device, $91.5 \%$ were treated with variable or continuous positive pressure ventilation (87.3\% APAP, $4.2 \%$ CPAP).

\section{Long-term adherence}

A total of $63.4 \%$ patients $(95 \% \mathrm{Cl}$ : $60.5-67.4)$ presented good adherence to home ventilation therapy, considering the utilization of the device as more than 4 hours a day, at least $70 \%$ of days.

Variables associated with best adherence were age [OR $=1.029$ (95\% Cl: 1.011-1.048), $p=0.014]$, using BIPAP versus CPAP [OR $=4.769(95 \% \mathrm{Cl}: 1.028-22.120), p=0.046]$, primary economic sector vs tertiary sector $[\mathrm{OR}=2.008(95 \% \mathrm{Cl}: 1.154-$ $-3.495), p=0.014]$, room sharing [OR $=2.865$ (95\% Cl: $1.455-$ $-5.640), p=0.002$ ] and severe versus mild OSA [OR $=1.899$ (95\% Cl: 1.016-3.548), $p=0.044]$. There were no differences between gender, educational level, economic status, workforce situation, BMI, smoking habits or distance from home to healthcare facilities.

\section{Costs related to non-adherence to home ventila- tion therapy}

To assess the annual costs related to non-adherence to ventilation therapy, we subdivided the population into four differ- ent categories (Table 2): adherent and non-adherent patients according to the definition related above and patients with inappropriate use of the device (non-utilization or utilization less than four hours per day).

We found the total cost associated with inappropriate use of the device to be $112,373.68 €$, which meant an annual cost per patient of $151.04 €$. Even in those who were considered adherent, we determined a total expenditure of $23,767.10 €$, mostly $(18,021.30 €)$ due to non-compliance with the 4 hours of use defined as the adherence criteria. As expected, we found a higher total expenditure in the non-adherent group when compared to the adherent group $(88,606.58 €$ vs $23,767.10 €)$, with per patient costs of $49.93 €$ and $330.62 €$, respectively, meaning that non-adherence wastes $238.38 €$ annually for each patient.

\section{Reasons of maladaptation}

Patients evoked several reasons for maladaptation to the device (Table 3). In general, the presence of leaks and nose lesions are more common in patients who adhered. Intolerance, problems with the mask, nasal obstruction and xerostomia were mostly noted by non-adherents $(p<0.001)$.

\begin{tabular}{|l|l|l|}
\hline \multicolumn{3}{|l|}{ Table 3. Reasons for maladaptation to the device } \\
\hline & $\begin{array}{l}\text { Non-adherents } \\
(n=131)\end{array}$ & $\begin{array}{l}\text { Adherents } \\
(n=213)\end{array}$ \\
\hline Xerostomia & 16 & 9 \\
\hline Nasal obstruction & 9 & 7 \\
\hline Problems with the mask & 9 & 2 \\
\hline Intolerance & 21 & 3 \\
\hline Lesion in the nose & 0 & 6 \\
\hline Leaks & 76 & 186 \\
\hline
\end{tabular}

\section{Discussion}

Our study shows that more than one third of patients suffering from OSA do not present adequate adherence to ventilatory therapy. This is in line with several other studies. Most European studies carried out in the last 10 years show that adherence to CPAP can vary from 50 to $90 \%$ [18-21]. A review of 82 studies showed that about a third of treated patients had poor adherence [22].

Our results revealed that patients with severe OSA at diagnosis evaluated through the sleep study had greater adherence than those with mild OSA. This outcome is corroborated by Baratta et al., who found a higher adherence to CPAP in the group with severe OSA [23]. We also verified that age is associated with better adherence to treatment, as found in another study [24]. Room sharing was also found as a predictor of CPAP adherence, as demonstrated in other studies [18, 25, 26]. In our study, a significant relationship between primary economic sector and treatment adherence was found. Mehrtash et al. also

\begin{tabular}{|l|l|l|l|}
\hline \multicolumn{2}{|l|}{ Table 2. Costs in euros related to non-adherence to home ventilation therapy } \\
\hline Costs & $\begin{array}{l}\text { Total } \\
(95 \% \mathrm{Cl})\end{array}$ & $\begin{array}{l}\text { Non-adherent* } \\
(95 \% \mathrm{CI})\end{array}$ & $\begin{array}{l}\text { Adherent** } \\
(95 \% \mathrm{Cl})\end{array}$ \\
\hline Non-utilization*** & $50,937.63$ & $45,191.83$ & $5,745.80$ \\
& $(45,142.32-56,732.93)$ & $(41,063.68-49,319.98)$ & $(5,062.74-6,428.86)$ \\
\hline Utilization less than 4 h/day & $61,436.05$ & $42,191.75$ & $18,021.30$ \\
& $(56,329.75-66,542.35)$ & $(39,442.32-44,941.18)$ & $(16,270.23-19,772.37)$ \\
\hline Total & $112,373.68$ & $88,606.58$ & $23,767.10$ \\
& $(103,334.48-121,412.88)$ & $(83,609.15-93,604.01)$ & $(21,572.61-25,961.59)$ \\
\hline
\end{tabular}

$\mathrm{Cl}$ - confidence interval.

* Patients with utilization of more than 4 hours a day, at least $70 \%$ of the days.

** Patents without utilization of more than 4 hours a day, at least $70 \%$ of the days.

$* * *$ Days without use of device. 
showed that patients with lower socioeconomic status, often associated with the primary economic sector, have greater adherence, probably because they are usually more receptive to medical counselling [25].

We found that the major problems in non-adherent patients are due to problems related to the machine itself (mask, nasal obstruction and xerostomia). In fact, they coincide with the problems most described in literature (dry mouth/throat, nasal symptoms and noise problems) $[27,28]$. However, given the modernization of devices, humidifiers and improvement of interfaces, it is necessary to determine if these problems effectively influence the cessation of therapy or if it is not associated with other psychosocial issues [28, 29].

A significant difference in adherence with CPAP and BiPAP was found in our study. This result differs from others, which did not demonstrate a difference in compliance between BiPAP and CPAP [30, 31]. Nonetheless, the shortage of patients in our study treated with these devices limits the interpretation of the results.

In our study, such as in literature, no significant relationship was found between $\mathrm{BMI}$, gender or working in the secondary economic sector and treatment compliance [18, 23-25].

We did not find any differences between the two types of continuous ventilation therapy devices (APAP and CPAP); nonetheless, evidence has shown that APAP promotes more comfort and compliance than CPAP, as it can be adjusted for pressure. However, there are few studies, and the results are not consistent [32]. We hypothesize that the absence of differences in our study is justified by the predominance of patients under APAP (87.3\%).

Contrary to our expectations, we did not establish a relationship between smoking habits and CPAP adherence. However, smokers seem to have worse compliance compared to non-smokers, apparently because they are less sensitive to medical counselling $[23,25]$.

Socioeconomic and educational levels can be considered partial predictors of CPAP adherence, as they influence the access to health resources. In Portugal, the ventilatory device is provided free of charge for all patients by the National Health Service, thus reducing the burden of socioeconomic pressure in adherence. Thus, it is not surprising we did not find a relation between economic status and adherence, unlike Riachi et al., who described better adherence to treatment with CPAP in patients with a higher socioeconomic level [18].

Even though no relationship was established with the level of education in our study, Bartlett et al. found that patients with greater "self-efficacy" (comprehension and ability to understand and handle the device and/or accessories) have greater adherence over time ( $70 \%$ of participants had completed high school, including $50 \%$ with higher education). We did not establish such a relationship, probably because most of the patients included (78.8\%) had studied less than 9 years [33].

Our study showed that, in 2018, non-adherence costs of ventilation therapy were $112,373.68 €$. Apart from the patient's compliance, the assessment of non-adherence costs is relevant, considering that the payment of the daily cost of ventilation therapy is made to the respiratory care supplier. This means that every time patients do not use the device, there is an unlimited resource that is wasted that does not contribute to health gains.

Although there are studies evaluating the total cost for the health system and the cost-effectiveness of CPAP therapy, literature lacks studies estimating the costs associated with non-adherence to this therapy, which do not allow for a comparison with our results [10-13].

Regarding the lack of studies estimating the costs associated with non-adherence to ventilation therapy in OSA, our study can be seen as an original work. One of its strengths is the sample size. Furthermore, although it is a retrospective study, the analyzed data was made up of objective values collected from reports, allowing us to reduce the memory bias frequently present in this type of study. Considering that patients with reports evaluating less than 180 days were excluded, we were able to assess the non-adherence after the initial period of adaptation, excluding patients who did not tolerate the device.

\section{Limitations of the study}

Our study has some limitations. This is a hospital-based study, in which patients were selected from a single center. The Epworth Scale is used to classify daily sleepiness and is often presented as a subjective evaluation of treatment satisfaction and adherence. Unfortunately, due to its shortage in clinical files, we were not able to include this parameter in our study. Although most patients with OSA are followed up in primary health care after the period of adaptation and initial adjustment to therapy, it is difficult to conduct a study in this area, since obtaining ventilatory therapy reports for all patients is currently not possible. Difficult access to the reports and the absence of their automatic inclusion in the electronic clinical file makes it difficult to offer the best care to patients with OSA.

\section{Conclusions}

The results obtained regarding adherence to ventilation therapy reflect the reality of patients followed up in hospital consultation. However, a large proportion of patients see their prescription renewed in primary health care, where compliance control is less likely due to the lack of a scheduled OSA consultation. With a view to reversing this reality, it is crucial that prescribers evaluate and encourage compliance with this therapy.

Currently, in Portugal, home respiratory care is $100 \%$ reimbursed by the National Health Service. The cost estimates presented refer to the amounts spent by this entity, which are not reflected objectively in health gains. In fact, the magnitude of this problem is substantially greater. What are the true costs of non-compliance with ventilation therapy?

This finding shows the importance of holding the patient accountable, reinforcing their role in treatment compliance and management.

Source of funding: This work was funded from the authors' own resources.

Conflicts of interest: The authors declare no conflicts of interest.

\section{References}

1. Senaratna CV, Perret JL, Lodge CJ, et al. Prevalence of obstructive sleep apnea in the general population: a systematic review. Sleep Med Rev 2017; 34: 70-81.

2. Ruehland WR, Rochford PD, O’Donoghue FJ, et al. The new AASM criteria for scoring hypopneas: impact on the apnea hypopnea index. Sleep 2009; 32(2): 150-157.

3. May AM, Mehra R. Obstructive sleep apnea: role of intermittent hypoxia and inflammation. Semin Respir Crit Care Med 2014; 35(5): 531-544.

4. Rodrigues AP, Pinto P, Nunes B, et al. Obstructive Sleep Apnea: epidemiology and Portuguese patients profile. Rev Port Pneumol 2017; 23(2): 57-61.

5. Shamsuzzaman ASM, Gersh BJ, Somers VK. Obstructive Sleep Apnea implications for cardiac and vascular disease. JAMA 2003; 290(14): 1906-1914. 
6. Shahar E, Whitney CW, Redline S, et al. Sleep-disordered breathing and cardiovascular disease: cross-sectional results of the Sleep Heart Health Study. Am J Respir Crit Care Med 2001; 163(1): 19-25.

7. Lee W, Nagubadi S, Kryger MH, et al. Epidemiology of Obstructive Sleep Apnea: a population-based perspective. Expert Rev Respir Med 2008; 2(3): 349-364.

8. Sullivan CE, Issa FG, Berthon-Jones M, et al. Reversal of obstructive sleep apnoea by continuous positive airway pressure applied through the nares. Lancet 1981; 1(8225): 862-865.

9. Kushida CA, Littner MR, Hirshkowitz M, et al. Practice parameters for the use of continuous and bilevel positive airway pressure devices to treat adult patients with sleep-related breathing disorders. Sleep 2006; 29(3): 375-380.

10. Streatfeild J, Hillman D, Adams R, et al. Cost-effectiveness of continuous positive airway pressure therapy for obstructive sleep apnea: health care system and societal perspectives. Sleep 2019; 42(12), doi: 10.1093/sleep/zsz181.

11. Ayas NT, FitzGerald JM, Fleetham JA, et al. Cost-effectiveness of continuous positive airway pressure therapy for moderate to severe obstructive sleep apnea/hypopnea. Arch Intern Med 2006; 166(9): 977-984.

12. Turino $\mathrm{C}$, Batlle $\mathrm{J}$ de, Woehrle $\mathrm{H}$, et al. Management of continuous positive airway pressure treatment compliance using telemonitoring in obstructive sleep apnea. Eur Respir J 2017; 49(2): 1601128.

13. Benedetto M de, Garbarino S, Sanna A. Obstructive sleep apnea (OSA): healthcare and social costs. Med Lav 2017; 108(4): 310-313, doi: $10.23749 / \mathrm{mdl} . v 108 i 4.6411$

14. Meslier N, Lebrun T, Grillier-Lanoir V, et al. A French survey of 3,225 patients treated with CPAP for obstructive sleep apnoea: benefits, tolerance, compliance and quality of life. Eur Resp J 1998; 12(1): 185-192.

15. Weaver TE, Sawyer AM. Adherence to continuous positive airway pressure treatment for obstructive sleep apnea: implications for future interventions. Indian J Med Res 2010; 131: 245-258.

16. Kribbs NB, Pack Al, Kline LR, et al. Objective measurement of patterns of nasal CPAP use by patients with obstructive sleep apnea. $A m$ Rev Respir Dis 1993; 147(4): 887-895.

17. SPMS. Condições de prestação de serviços de cuidados técnicos respiratórios domiciliários. Despacho 9483/2014. DR 139 - Série II (22/07/2014) (in Portugese).

18. Riachy M, Najem S, Iskandar M, et al. Factors predicting CPAP adherence in obstructive sleep apnea syndrome. Sleep Breath 2017; 21(2): 295-302.

19. Kohler M, Smith D, Tippett V, et al. Predictors of long-term compliance with continuous positive airway pressure. Thorax 2010; 65(9): 829-832.

20. Mendelson M, Gentina T, Gentina E, et al. Multidimensional evaluation of continuous positive airway pressure (CPAP) treatment for sleep apnea in different clusters of couples. J Clin Med 2020; 9(6): 1658, doi: 10.3390/jcm9061658.

21. Orth M, Kotterba S, Walther J, et al. Langzeit-Compliance der CPAP-Therapie - aktueller Stand, Prädiktoren und Interventionsmöglichkeiten. Pneumologie 2006; 60: 480-484 (in German).

22. Rotenberg BW, Murariu D, Pang KP. Trends in CPAP adherence over twenty years of data collection: a flattened curve. $J$ Otolaryngol Head Neck Surg 2016; 45: 43, doi: 10.1186/s40463-016-0156-0.

23. Baratta F, Pastori D, Bucci T, et al. Long-term prediction of adherence to continuous positive air pressure therapy for the treatment of moderate/severe obstructive sleep apnea syndrome. Sleep Med 2018; 43: 66-70.

24. Palm A, Midgren B, Theorell-Haglöw J, et al. Factors influencing adherence to continuous positive airway pressure treatment in obstructive sleep apnea and mortality associated with treatment failure - a national registry-based cohort study. Sleep Med 2018; 51: 85-91.

25. Mehrtash M, Bakker JP, Ayas N. Predictors of continuous positive airway pressure adherence in patients with obstructive sleep apnea. Lung 2019; 197(2): 115-121.

26. Ye L, Malhotra A, Kayser K, et al. Spousal involvement and CPAP adherence: a dyadic perspective. Sleep Med Rev 2015; 19 : 67-74.

27. Ryswyk E van, Anderson CS, Antic NA, et al. Predictors of long-term adherence to continuous positive airway pressure in patients with obstructive sleep apnea and cardiovascular disease. Sleep 2019; 42(10): zsz152, doi: 10.1093/sleep/zsz152.

28. Luyster FS, Strollo PJ Jr, Thunström E, et al. Long-term use of continuous positive airway pressure therapy in coronary artery disease patients with non-sleepy obstructive sleep apnea. Clin Cardiol 2017; 40(12): 1297-1302.

29. Mador MJ, Krauza M, Pervez A, et al. Effect of heated humidification on compliance and quality of life in patients with sleep apnea using nasal continuous positive airway pressure. Chest 2005; 128(4): 2151-2158.

30. Reeves-Hoché MK, Hudgel DW, Meck R, et al. Continuous versus bilevel positive airway pressure for obstructive sleep apnea. Am J Respir Crit Care Med 1995; 151(2 Pt 1): 443-449.

31. Gay PC, Herold DL, Olson EJ. A randomized, double-blind clinical trial comparing continuous positive airway pressure with a novel bilevel pressure system for treatment of obstructive sleep apnea syndrome. Sleep 2003; 26(7): 864-869.

32. Broström A, Pakpour AH, Nilsen P, et al. Promoting CPAP adherence in clinical practice: a survey of Swedish and Norwegian CPAP practitioners' beliefs and practices. J Sleep Res 2018; 27(6): e12675, doi: 10.1111/jsr.1267533.

33. Bartlett $\mathrm{D}$, Wong $\mathrm{K}$, Richards $\mathrm{D}$, et al. Increasing adherence to obstructive sleep apnea treatment with a group social cognitive therapy treatment intervention: a randomized trial. Sleep 2013; 36(11): 1647-1654.

Tables: 3

Figures: 0

References: 33

Received: 8.08.2020

Reviewed: 12.12 .2020

Accepted: 15.02.2021

Address for correspondence:

Joana Peixoto, MD

USF Mais Saúde - Alto Minho Local Heath Unit

Rua da Cidade Châlette-sur-Loing 67

4990-084 Ponte de Lima

Portugal

Tel.: +351962423883

E-mail: joana.speixoto@gmail.com 